\title{
Detection of a Single-Copy Plasmid, pXFSL21, in Xylella fastidiosa Strain Stag's Leap with Two Toxin-Antitoxin Systems Using Next-Generation Sequencing
}

\author{
Christopher Van Horn, Fengnian Wu, Zheng Zheng, Zehan Dai, and Jianchi Chen ${ }^{\dagger}$
}

First and fifth authors: United States Department of Agriculture-Agricultural Research Service San Joaquin Valley Agricultural Sciences Center, Parlier, CA 93648, USA; and second, third, and fourth authors: Department of Plant Pathology, South China Agricultural University, Guangzhou, Guangdong, China.

Accepted for publication 24 October 2018.

\begin{abstract}
Plasmids are important genetic elements contributing to bacterial evolution and environmental adaptation. Xylella fastidiosa is a nutritionally fastidious Gram-negative bacterium causing economically devastating diseases such as Pierce's disease (PD) of grapevine. In this study, the plasmid status of a highly virulent PD strain, Stag's Leap, originally isolated from Napa Valley, CA, was studied using sequencing and bioinformatics tools. DNA samples extracted from a pure culture in periwinkle wilt medium (in vitro DNA) and a PD-symptomatic grapevine artificially inoculated in the greenhouse (in planta DNA) were subject to next-generation sequencing (NGS) analyses (Illumina MiSeq or HiSeq). Sequence analyses and polymerase chain reaction experiments revealed the presence of a circular plasmid, pXFSL21, of 21,665 bp. This plasmid

existed as a single copy per bacterial genome under both in vitro and in planta conditions. Two toxin-antitoxin (T-A) systems $(y d c D-y d c E$ and higB-higA) were detected in pXFSL21, a possible mechanism for the long-term survival of this single-copy plasmid in the bacterial population. BLAST searches against the GenBank database (version 222) detected homologs of the two T-A systems in chromosomes or plasmids of some $X$. fastidiosa strains. However, double T-A systems were found only in pXFSL21. pXFSL21 was not found in other known PD strains and, therefore, could serve as a molecular marker for strain Stag's Leap monitoring and tracking. The NGS-based technique outlined in this article provides an effective tool for identifying single- or low-copy-number plasmids in fastidious prokaryotes.
\end{abstract}

Plasmids are self-replicating, extrachromosomal genetic elements responsible for horizontal gene transfer that contribute to bacterial evolution and environmental adaptation, including virulence (Coplin 1989). High-copy-number plasmids are well known for biotechnological manipulations such as DNA fragment cloning. However, many bacterial plasmids such as those associated with environmental adaptation could be at a low copy number or even single copy. Low-copy plasmids are advantageous for survival by lowering host metabolic burdens (Sternberg and Austin 1981). Virulence plasmids are often large ( $>20 \mathrm{kbp})$, because they carry genes for functions of replication, dissemination, and maintenance (RDM) in addition to those conferring advantageous phenotypes (CAPs) (Sengupta and Austin 2011).

Xylella fastidiosa is a Gram-negative, xylem-limited, bacterial pathogen causing diseases in many economically important plants; for example, Pierce's disease (PD) of grapevine in California and the southeastern United States (Hopkins 1989), citrus variegated chlorosis (CVC) in Brazil (Chang et al. 1993), and olive quick decline syndrome (OQDS) in Italy (Giampetruzzi et al. 2015; Saponari et al. 2013). Due to its nutritional fastidiousness, research on X. fastidiosa has been highly challenging. A 1.3-kbp plasmid was observed in an $X$. fastidiosa periwinkle wilt (PW) strain (Chen et al. 1992) and sequenced by Sanger's method (Pooler and Hartung 1997). Concurrent with a significant increase in $X$. fastidiosa research since the 2000s due to outbreaks of PD, CVC, and OQDS, in total, 46 plasmids ranging from 1.3 to $64 \mathrm{kbp}$ in size have been

†Corresponding author: Jianchi Chen; E-mail: Jianchi.Chen@ARS.USDA.GOV

*The $e$-Xtra logo stands for "electronic extra" and indicates that one supplementary figure and three supplementary tables are published online.

(c) 2019 The American Phytopathological Society identified, annotated, and deposited in the GenBank database (version 222) (Supplementary Table S1). Most of the plasmid discoveries were derived from whole-genome sequencing efforts, particularly the use of next-generation sequencing (NGS) technology. Thirty-three of the $X$. fastidios $a$ plasmids are $>20 \mathrm{kbp}$ in size. In all cases, copy numbers of the sequenced plasmids were not estimated, with the exception of the PW plasmid, estimated to be at least 60 copies per genome (Chen et al. 1992).

Although in low copy number, large plasmids have intricate mechanisms for their maintenance in bacterial populations. One mechanism is the toxin-antitoxin (T-A) system (Gerdes et al. 1986; Hayes 2003). In the T-A system, a plasmid encodes a stable toxin and a labile antitoxin. Daughter cells without the plasmid will be killed by the toxin because the unstable antitoxin is degraded. Such a phenomenon is also called postsegregational killing (Gerdes et al. 1986). The presence of T-A systems in X. fastidiosa were detected through genome sequence analyses (Pandey and Gerdes 2005), and functions of the plasmid-borne T-A system (pemI/pemK) have been confirmed in vitro (Lee et al. 2014; Stenger et al. 2010). T-A systems have also been found in bacterial chromosomes and received extensive research in light of mechanisms of virulence and programing cell death (Burbank and Stenger 2016; Pandey and Gerdes 2005).

The Stag's Leap strain of $X$. fastidiosa subsp. fastidiosa was originally isolated from Napa Valley in California (Buzkan et al. 2005) and has been commonly used as a model for PD research because of its high virulence (Krivanek and Walker 2005; Krugner et al. 2014; Wallis et al. 2013). We are interested in further studying the biology of this model strain using NGS technology and bioinformatics tools. Toward this end, a draft whole-genome sequence of the Stag's Leap strain was obtained (Chen et al. 2016). Based on available genomic sequence data, this study evaluated the plasmid status of this strain through both in vitro and in planta 
experiments and analyses. A single-copy plasmid, pXFSL21, with two T-A systems was identified. Implications of using an NGS approach to study plasmids in X. fastidiosa and other fastidious prokaryotes are also discussed.

\section{MATERIALS AND METHODS}

Bacterial strains and DNA samples. $X$. fastidiosa strain Stag's Leap was maintained on PW medium (Davis et al. 1981) at $28^{\circ} \mathrm{C}$, with regular transfer every 20 to 30 days since 2010 . Bacterial DNA was obtained from both in vitro and in planta sources. For the in vitro sample, cells were collected from culture (14 days) and DNA was extracted according to a standard procedure (Maniatis et al. 1982). For in planta samples, a grapevine (Vitis vinifera), cultivar Thompson Seedless, grown in the greenhouse for 4 months, was inoculated twice on the stem using the pinprick method with $10-\mu l$ drops of $X$. fastidiosa cell suspension using a 20-guage syringe needle (Hopkins 2001). Twelve weeks after inoculation, PD symptoms on leaves (marginal necrosis) were observed and the most severe symptoms were near the site of inoculation. Leaf petiole samples were collected and macerated with an automated tissue homogenizer (Geno/Grinder; SPEX SamplePrep, Metuchen, NJ). DNA was extracted using the NucleoSpin Plant II kit (MachereyNagel, Düren, Germany), quantified and used for polymerase chain reaction (PCR) or sequencing experiments. The presence of $X$. fastidiosa in the sample was confirmed by standard PCR with primer sets Teme150fc-Teme454rg and Dixon454fc-Dixon1261rg (Chen et al. 2005). Additionally, primer set Teme150fc-Teme454rg was used for quantitative real-time PCR (qPCR) with SYBR green.

DNA sequencing and whole-genome assembly. NGS experiments were performed through a commercial service. A brief description on sequencing the Stag's Leap genome from in vitro culture DNA with the Illumina MiSeq $2 \times 300$ platform has been published (Chen et al. 2016). The in planta sample (mixture of both $X$. fastidiosa and grapevine DNA) was sequenced by Illumina HiSeq $2 \times$ 100 (Illumina, Inc., San Diego, CA). With sequence reads from either MiSeq (in vitro) or HiSeq (in planta), both referenced and de novo assemblies were performed using CLC Genomics Workbench software (v. 10.1.1). For reference assembling of HiSeq reads (in planta), default parameters were used. The published Stag's Leap genome sequence (NZ_LSMJ00000000.1) (Chen et al. 2016) was used as a reference. For de novo assembling, parameters were as follows; word size $=64$, bubble size $=200$, minimum contig length $=$ 250 , mismatch $\operatorname{cost}=2$, insertion $\operatorname{cost}=3$, deletion $\operatorname{cost}=3$, length fraction $=0.6$, and similarity fraction $=0.9$.

Plasmid detection. Two approaches were used for plasmid screening in the draft Stag's Leap genome sequence (NZ_LSMJ00000000.1). (i) One approach identified contigs with high similarity to the known $X$. fastidiosa plasmids. The 46 $X$. fastidiosa plasmid sequences in GenBank were downloaded. The 15 contigs in the draft Stag's Leap genome were used as queries to BLAST search against the $46 X$. fastidios $a$ plasmids (word size $=$ 7 , e-value $\left.=1 \mathrm{e}^{-10}\right)$. Contigs with high bit score were selected as candidate plasmids. (ii) Another approach analyzed contigs for typical plasmid structures. Annotation of the 15 contigs in NZ_LSMJ00000000.1 through the RAST server (http://rast.nmpdr. org/) (Aziz et al. 2008) were examined for the simultaneous presence of genes associated with both RDM and CAP (Coplin 1989).

Plasmid sequence enclosure, annotation, and protein threedimensional structure analyses. Contig 15 of NZ_LSMJ00000000.1 was identified as a plasmid candidate. Two approaches were used to prove circularity. (i) One approach involved in silico read mapping, as previously described (Zheng et al. 2018). Briefly, a 5,000 -bp section (A) at the $5^{\prime}$ end of contig 15 was cut and attached to the $3^{\prime}$ end of the remaining region (B) to make sequence B-A. As a control, a 5,000-bp sequence randomly selected from nucleotide position 564,797 to $569,797 \mathrm{bp}$ of contig 1 (designated as C) was cut and attached to region $\mathrm{B}$ to replace $\mathrm{A}$ and make sequence $\mathrm{B}-\mathrm{C}$.
Both sequences B-A and B-C were used as the references for mapping with both MiSeq and HiSeq reads and check for smooth read transition (Supplementary Fig. S1). (ii) Another approach involved PCR and sequencing. Primers were designed from both the $5^{\prime}$ and $3^{\prime}$ ends of contig 15 with outward directionality (primer sets 21250F-137R and 21124F-617R) (Supplementary Table S3). Primer3Plus (Untergasser et al. 2007) was used to assist primer designs. Amplicons of standard PCR were further sequenced through the Sanger method on an Applied Biosystems 3130xl Genetic Analyzer. To search for chromosomal integration, contig 15 was used as a query to BLAST search against the other 14 contigs in NZ_LSMJ00000000.1 for highly similar regions. CLC Genomics software was used to view gene orientation and annotation and to generate the genetic map.

Protein structure analysis of selected genes was initially predicted in the Phyre server (http://www.sbg.bio.ic.ac.uk/ phyre $2 / \mathrm{html} /$ page.cgi?id=index) using a profile-profile alignment algorithm (Kelley et al. 2015). Final three-dimensional (3D) structure was optimized by using PyMOL Molecular Graphics System, version 2.0 (Schrödinger LLC).

Copy number estimation. Two methods were used to estimate plasmid copy number. (i) The first method was comparison of average nucleotide coverages (ANCs) between plasmid candidate and chromosomal contig sequences, as well as selected plasmid and chromosomal genes, through read mapping using MiSeq and HiSeq data. The ANC ratio of plasmid/chromosomal sequence were calculated. (ii) The second method was comparison of cycle threshold $(\mathrm{Ct})$ values between plasmid-specific gene primer sets and chromosome-specific gene primer sets. Primer sets were designed to generate 200-bp amplicons. The single-copy glyceraldehyde 3-phosphate dehydrogenase $(G A P D H)$ gene was used as a reference to estimate the copy number of the target plasmid gene by

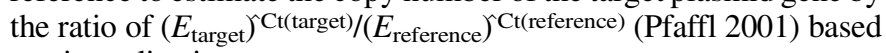
on six replications.

PCR procedures and statistical analyses. Standard PCR was performed according to a previous report (Chen et al. 2005). Briefly, PCR $(20 \mu \mathrm{l})$ was carried out using the Takara Taq (Hot Start Version) kit (Takara Bio Inc., Otsu, Japan). The reaction mixture contained $10 \mathrm{mM}$ Tris- $\mathrm{HCl}, \mathrm{pH}$ 8.3; $50 \mathrm{mM} \mathrm{KCl} ; 1.5 \mathrm{mM} \mathrm{MgCl}$; $100 \mu \mathrm{M}$ each dNTP; $0.5 \mu \mathrm{M}$ each primer; 1 unit of Taq DNA polymerase; and $1 \mu \mathrm{l}$ of cell suspension. Amplification was conducted in a thermocycler (Model PTC-100; MJ Research, Waltham, MA) with an initial denature at $98^{\circ} \mathrm{C}$ for 5 min followed by 30 cycles consisting of denaturing at $96^{\circ} \mathrm{C}$ for $30 \mathrm{~s}$, annealing at $55^{\circ} \mathrm{C}$ for $15 \mathrm{~s}$, and extension at $72^{\circ} \mathrm{C}$ for $60 \mathrm{~s}$. The amplification products were then stored at $4^{\circ} \mathrm{C}$. The amplified DNAs were resolved through $1.5 \%$ agarose gel electrophoresis and visualized after staining.

For qPCR, the DNA sample was diluted to $2 \mathrm{ng} / \mu \mathrm{l}$ in pure water. Using Fast SYBR Green Master Mix (Thermo Fisher Scientific, Waltham, MA), qPCR reactions were set up containing $2 \mu 1$ of DNA template, $2 \times$ Fast SYBR Green Master Mix (containing AmpliTaq Fast DNA polymerase, dNTPs, SYBR Green I dye, ROX dye passive reference, $\mathrm{MgCl}_{2}$, and stabilizers), and $0.25 \mu \mathrm{M}$ each of forward and reverse primers for a final reaction volume of $20 \mu \mathrm{l}$.

Homologs of T-A system genes. Each T-A system gene sequence was used as query to BLAST search against the GenBank $\mathrm{nr}$ and whole-genome shotgun sequence database (version 222) that included 46 plasmids and 41 whole-genome sequences of $X$. fastidiosa (Supplementary Table S2) with word size $=11$ and expected threshold $=10$. Homologs were evaluated by query coverage and sequence identity. Similarly, related non- $X$. fastidiosa bacteria were identified.

\section{RESULTS}

DNA sequencing and whole-genome assembly. Selected metrics of Illumina MiSeq and HiSeq sequencing and the derived assemblies are shown in Table 1. MiSeq generated 6 million 301-bp 
reads with a total of nearly 2 giga bp. HiSeq generated $>300$ million $101-b p$ reads with a total of nearly 32 giga bp. However, the HiSeq data were a mixture of sequences of both grape and $X$. fastidiosa. The Xylella DNA was estimated to be approximately $2 \%$ $[(2,316,903 \times 508$ ANC)/31,935,159,902] (Tables 1 and 2). Metrics of $X$. fastidiosa-only were shown under reference mapping, with 493 contigs $(2,272,127$ bp) from MiSeq and 235 contigs (2,316,903 bp) from HiSeq covering the draft Stag's Leap genome sequence (NZ_LSMJ00000000.1). Adding all de novo contigs with $\geq 1,000 \mathrm{bp}$, the draft genome size from in vitro DNA $(2,170,878 \mathrm{bp}$ in 77 contigs) and the draft genome size from in planta DNA (2,297,788 bp in 104 contigs) were comparably similar but not identical, likely due to variations in assembling processes.

Plasmid detection. Contig 15 of NZ_LSMJ00000000.1 (Table 2) was identified to be a plasmid because (i) according to annotation, the contig with 27 open reading frames (ORFs) contained both RDM genes (14 ORFs: ORF1, 5, 8, 9, and 18 to 27) and CAP genes (2 ORFs: ORF13 and 14) (Table 3); (ii) contig 15

TABLE 1. Comparison of selected metrics of MiSeq (in vitro) and HiSeq (in planta) experiments and genome assembly of Xylella fastidiosa strain Stag's Leap

\begin{tabular}{|c|c|c|}
\hline & In vitro - MiSeq & In planta - HiSeq \\
\hline Parameter & Xylella & Xylella + Vitis \\
\hline Total bases & $1,982,951,278$ & $31,935,159,902^{\mathrm{a}}$ \\
\hline Total reads & $6,587,878$ & $316,189,702$ \\
\hline Read length & 301 & 101 \\
\hline \multicolumn{3}{|l|}{ De novo assembly } \\
\hline Number of contigs & 952 & 418,979 \\
\hline Minimum contig length & $263 \mathrm{bp}$ & $192 \mathrm{bp}$ \\
\hline Maximum contig length & $300,673 \mathrm{bp}$ & $230,620 \mathrm{bp}$ \\
\hline Contig N50 & $93,115 \mathrm{bp}$ & $2,512 \mathrm{bp}$ \\
\hline Number of contigs $\geq 1,000 \mathrm{bp}$ & 127 & 97,751 \\
\hline \multicolumn{3}{|l|}{ Referenced mapping } \\
\hline \multicolumn{3}{|l|}{$\begin{array}{l}\text { With NZ_LSMJ00000000.1 } \\
\text { (15 contigs) }\end{array}$} \\
\hline $\begin{array}{l}\text { Number of de novo } \\
\text { contigs mapped }\end{array}$ & $493(2,272,127 \mathrm{bp})$ & $235(2,316,903 \mathrm{bp})^{\mathrm{b}}$ \\
\hline Contigs $\geq 1,000 \mathrm{bp}$ & $77(2,170,878$ bp $)$ & $104(2,297,788 \mathrm{bp})$ \\
\hline \multicolumn{3}{|l|}{ With pXFSL21 } \\
\hline $\begin{array}{l}\text { Number of de novo } \\
\text { contigs mapped }\end{array}$ & $2(21,868 \mathrm{bp})$ & $4(21,718 \mathrm{bp})$ \\
\hline
\end{tabular}

a Only the forward reads were used.

b Average nucleotide coverage $=508 x$. had high BLAST bit scores $(>8,000)$ to four $X$. fastidiosa plasmids (pXF-P4.OLS0478, pXF-P4.OLS0479, pXF-De Donno, and unnamed from CoDiRO); (iii) MiSeq read mapping showed continuity in the connection of $5^{\prime}$ and $3^{\prime}$ ends; and (iv) PCR primer sets 21250F-137R and 21124F-617R (Fig. 1B) amplified the expected DNA bands (Fig. 1C). The enclosure was further confirmed by Sanger sequencing of the amplicons. Therefore, contig 15 was designated as pXFSL21 (Fig. 1B). pXFSL21 derived from two de novo contigs of MiSeq data (in vitro DNA) or four de novo contigs of HiSeq data (in planta DNA) (Table 1). The sequence of pXFSL21 has been deposited in GenBank under the accession number MG879030.

Among the 27 ORFs, 22 had predicted gene functions, including 3 DNA primase, 2 resolvase/integrase, 8 in the $t r b$ conjugative transfer family, 4 that formed two pairs of T-A systems ( $y d c D-y d c E$, and higB-higA), and 4 in a multidrug efflux pump system involving acriflavine resistance (Table 3). The 3D structures of the two T-A systems proteins are shown in Figure $2 \mathrm{~A}$ to $\mathrm{D}$.

Copy number estimation. ANCs of both MiSeq and HiSeq data to the 15 contigs of the draft Stag's Leap genome sequences were listed in Table 2 . Note that contig 15 was renamed as pXFSL21 $(\mathrm{GC} \%=50.1)$. Contig 12 had a size of $21,851(\mathrm{GC} \%=50.4)$, similar to that of pXFSL21. ORF analyses of contig 12 did not reveal typical RDM and CAP genes. Instead, four tRNA genes (tRNA-arg, tRNApro, tRNA-his, and tRNA-lys), typically chromosome borne, were found. Therefore, contig 12 was used as a chromosome reference to pXFSL21 for ANC ratio calculations. For in vitro experiments, ANC-pXFSL21/ANC-contig 12 was 1.09 (441/403) (Table 2). For in planta experiments, ANC-pXFSL21/ANC-contig was 0.98 (481/ 492) (Table 2). The near one-to-one ANC ratios suggested that pXFSL2 1 is single copy per genome of $X$. fastidiosa under both in vitro and in planta conditions.

Results of ANC analyses at a gene level are shown in Table 4. Using the double-copied chromosomal gene of $16 \mathrm{~S}$ ribosomal RNA (rRNA) (rrs) as a reference, all selected pXFSL21 genes assembled from MiSeq (in vitro DNA) data had ANC ratios to rrs of approximately 0.5 (0.37 to 0.59 ), with the exception of $d n a G l$. BLAST search with pXFSL21 as query detected an identical copy of dnaGl in contig 2 (Fig. 1A). Therefore, this gene is double copied, one in the chromosome and the other in pXFSL21 (Fig. 1B).

In the HiSeq (in planta DNA) data mapping, ANC of rrs was extraordinarily high $(55,770 \times)$ (Table 4$)$. This was not surprising due to the conserved nature of $16 \mathrm{~S}$ rRNA sequences between the

TABLE 2. Comparison of average nucleotide coverages (ANCs) on mapping the draft genome sequence of Xylella fastidiosa strain Stag's Leap (NZ_LSMJ00000000.1) between MiSeq (in vitro) and HiSeq (in planta) data ${ }^{\mathrm{a}}$

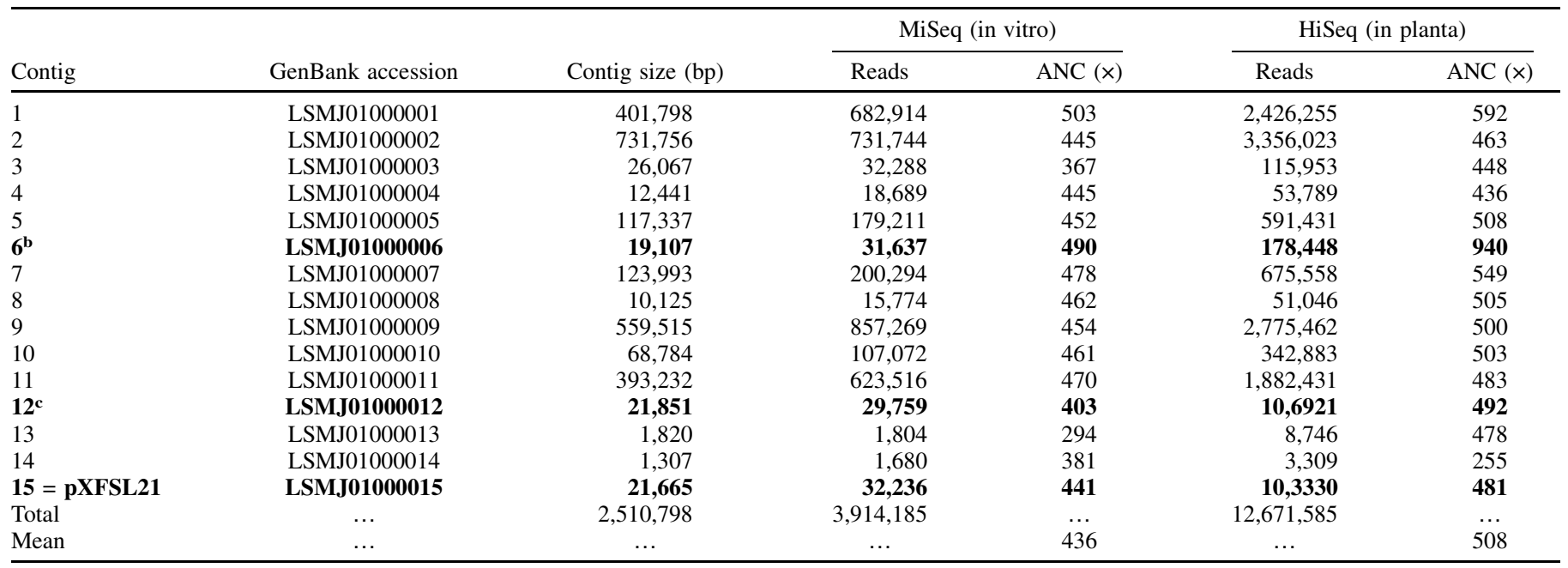

a Contigs in bold were the focus of this study.

b Contig 6 has an almost doubled ANC value (940x) compared with those of other contigs in the in planta data.

c Contig 12 is a reference to pXFSL21 for ANC comparison because of the similar size. 
plant chloroplast and bacteria. The double-copied dnaGl gene sequence was then used as reference for the ANC ratio calculation. All selected pXFSL21 genes showed the ratio of approximately 0.5 (0.44 to 0.56 ) (Table 4). As a control, all selected single-copy chromosomal genes also showed a ratio of approximately $0.5(0.36$ to 0.56$)$.

PCR experiments comparing plasmid genes tetR and $a c r B$ to the singled-copied chromosomal GAPDH gene showed copy numbers

TABLE 3. General information of pXFSL21 from Xylella fastidiosa strain Stag's Leap

\begin{tabular}{|c|c|c|c|c|c|}
\hline $\mathrm{ORF}^{\mathrm{a}}$ & Gene name & Position & Base pairs & Amino acids & Annotation $^{\mathrm{b}}$ \\
\hline 1 & dnaG1 & 129-1,202 & 1,074 & 357 & DNA primase \\
\hline 2 & ORF & $1,318-1,773$ & 456 & 151 & Hypothetical protein \\
\hline 3 & ORF & $2,042-2,596$ & 555 & 184 & Hypothetical protein \\
\hline 4 & ORF & $2,628-3,092$ & 465 & 154 & Hypothetical protein \\
\hline 5 & $n i k$ & $3,571-3,684$ & 114 & 37 & Nickase \\
\hline 6 & ORF & $3,814-4,281$ & 468 & 155 & Hypothetical protein \\
\hline 7 & ORF & $4,505-4,657$ & 153 & 50 & Hypothetical protein \\
\hline 8 & $\operatorname{inv} A$ & $4,856-5,050$ & 195 & 64 & DNA invertase \\
\hline 9 & $r s v B$ & $5,054-5,437$ & 384 & 127 & DNA resolvase \\
\hline 10 & $y d c D$ & $5,593-5,775$ & 183 & 60 & Antitoxin \\
\hline 11 & $y d c E$ & $5,884-6,198$ & 315 & 104 & Toxin \\
\hline 12 & oarl & $6,865-7,671$ & 807 & 268 & 3-oxoacyl-reductase \\
\hline 13 & $a c r B$ & 7,717-10,779 & 3,063 & 1,020 & Acriflavine resistance protein \\
\hline 14 & acrA & $10,776-11,882$ & 1,107 & 368 & Multidrug efflux protein \\
\hline 15 & tetR & $11,964-12,581$ & 618 & 205 & Transcriptional regulator \\
\hline 16 & $\operatorname{hig} A$ & $12,834-13,124$ & 291 & 96 & Antitoxin \\
\hline 17 & higB & $13,142-13,420$ & 279 & 92 & Toxin \\
\hline 18 & $\operatorname{trbJ}$ & $13,479-13,685$ & 207 & 68 & Conjugative transfer protein \\
\hline 19 & $\operatorname{trbI}$ & $13,698-14,546$ & 849 & 282 & Conjugative transfer protein \\
\hline 20 & $\operatorname{trbF}$ & $14,608-15,324$ & 717 & 238 & Conjugative transfer protein \\
\hline 21 & $\operatorname{trb} E$ & $15,321-17,132$ & 1,812 & 603 & Conjugative transfer protein \\
\hline 22 & $\operatorname{trbE}$ & $17,714-17,884$ & 171 & 56 & Conjugative transfer protein \\
\hline 23 & $\operatorname{trbD}$ & $17,872-18,138$ & 267 & 88 & Conjugative transfer protein \\
\hline 24 & $\operatorname{trb} C$ & $18,195-18,587$ & 393 & 130 & Conjugative transfer protein \\
\hline 25 & $\operatorname{trbB}$ & $18,600-19,481$ & 882 & 293 & Conjugative transfer protein \\
\hline 26 & dnaG2 & $19,512-19,886$ & 375 & 124 & DNA primase \\
\hline 27 & dnaG3 & $19,966-20,769$ & 804 & 267 & DNA primase \\
\hline
\end{tabular}

a ORF = open reading frame. Rows of ORFs 10,11,16, and 17 are in bold to highlight the toxin-antitoxin system genes.

b Annotation was performed through the RAST server (http://rast.nmpdr.org/).

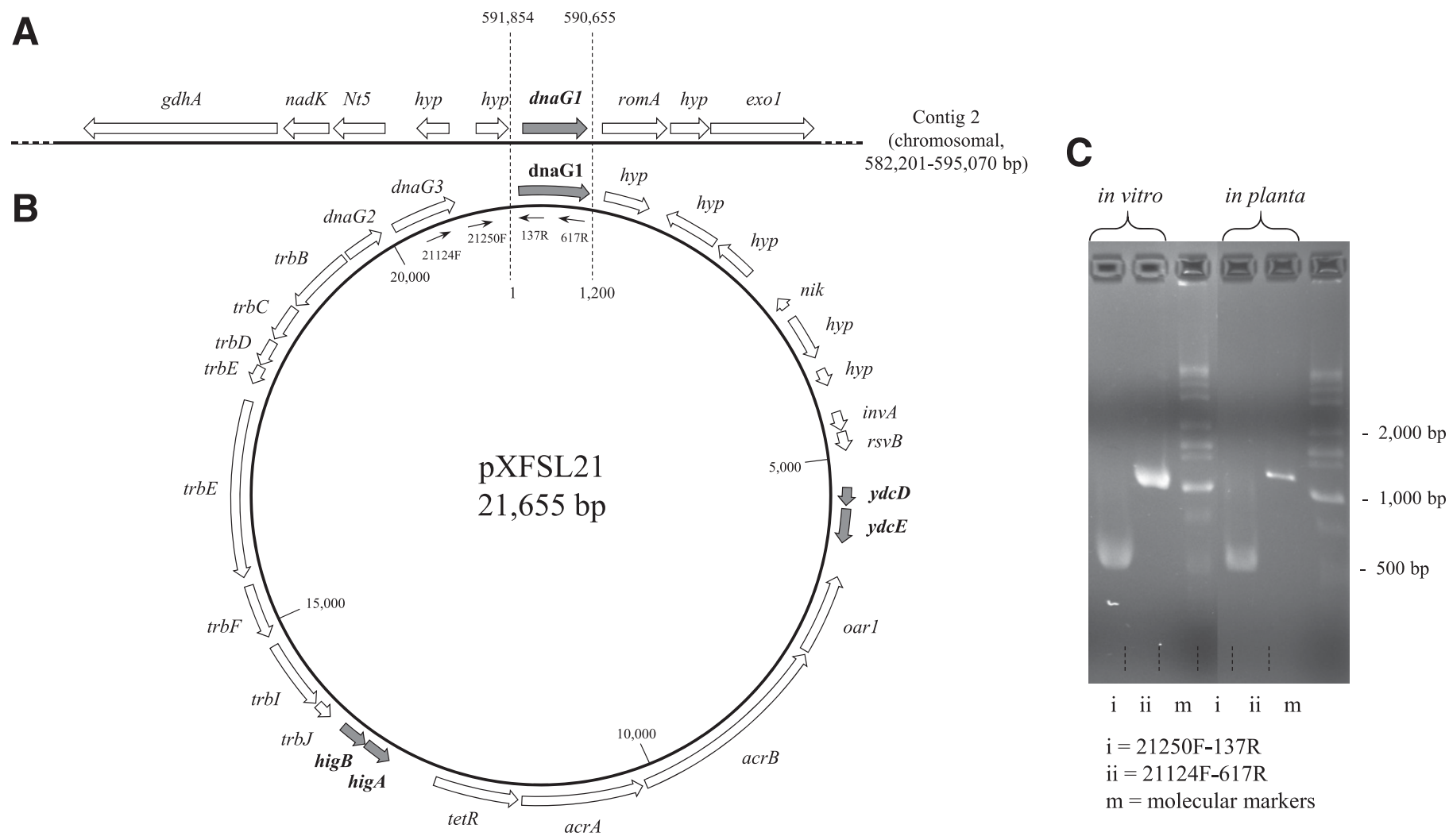

Fig. 1. Schematic descriptions of pXFSL21. A, Chromosomal integration of $d n a G$. Annotation of selected genes: $g d h A=$ NAD-specific glutamate dehydrogenase, $n a d K=$ NAD kinase, $N t 5=5^{\prime}$-nucleotidase, hyp $=$ hypothetical protein, $r o m A=$ outer membrane protein, and exol = exodeoxyribonuclease I. B, Circular pXFSL21 with annotated genes and open reading frames. The two toxin-antitoxin systems ( $y d c D-y d c E$ and higB-higA) are highlighted. Solid single-line arrows are relative positions of primers used for polymerase chain reaction (PCR) enclosure experiments. C, Agarose gel electrophoresis of PCR amplicons from enclosure primer sets (21250F-137R and 21124F-617R) from in vitro and in planta experiments. 
of 1.16 and 0.84 , respectively, with the in vitro DNA, and 1.13 and 1.16, respectively, with the in planta DNA (Table 5). These results further supported the conclusions from in silico analyses that pXFSL21 was a single-copy plasmid in strain Stag's Leap.

Homologs of pXFSL21 T-A systems. Homologs of $y d c D$ $y d c E$ were detected in $26 X$. fastidiosa GenBank sequence records (10 plasmids and 16 whole-genome sequences) (Table 6). Based on sequence similarity, a gene in plasmid PP1 of Pseudomonas syringae was highly related to $y d c D$, and a gene in plasmid $\mathrm{pP} 2$ of Xanthomonas citri was highly similar to $y d c E$. The predicted 3D structure of $y d c E$ protein, or $\mathrm{YdcE}$, was not similar to the representative structure of the $\mathrm{YdcE} / \mathrm{MazF} / \mathrm{PemK}$ family of endoribonuclease functions (Pellegrini et al. 2005). Homologs of higB-higA were detected in only two Xylella fastidiosa strains, Ann-1 and CO33 (Table 7). The closest bacterium with the higB-higA homolog was Sphingobium cloacae with its plasmid pSCLO_4. The predicted 3D structures of both HigB and HigA were very similar to the those of a Proteus vulgaris strain (Schureck et al. 2014).

\section{DISCUSSION}

Traditionally, plasmids are identified by their unique physical features (compared with chromosomal DNA) such as supercoiled conformation and small size through appropriate experimental

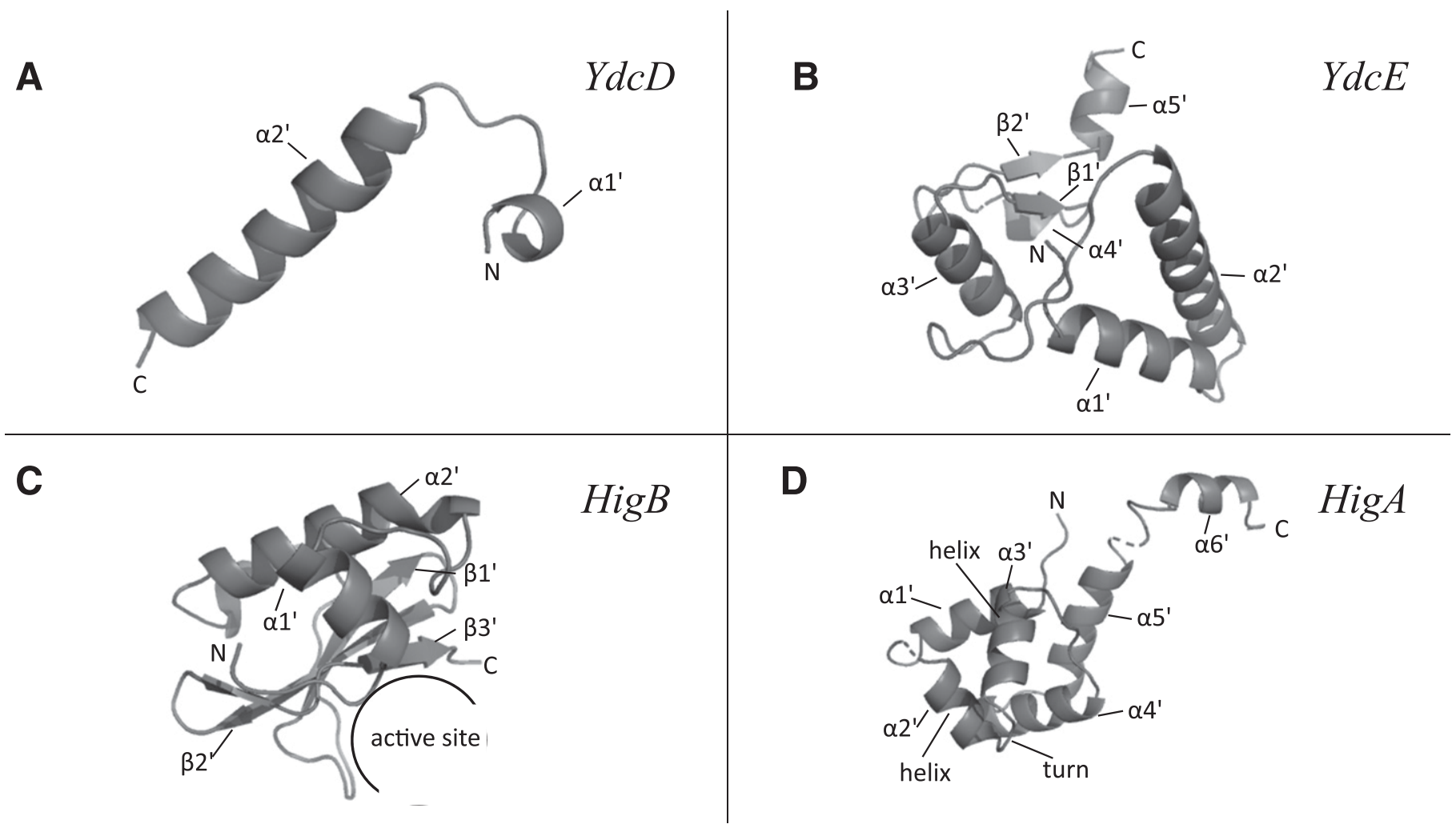

Fig. 2. Predicted three-dimensional structure, by Phyre2, of proteins encoded by A, $Y d c D ; \mathbf{B}, Y d c E ; \mathbf{C}, H i g B$; and $\mathbf{D}, H i g A$. $\mathrm{N}=\mathrm{N}$ terminal and C = C terminal. The helix-turn-helix motif in higA is the DNA binding site.

TABLE 4. Average nucleotide coverage (ANC) analyses of selected genes from pXFSL21 and Xylella fastidiosa strain Stag's Leap chromosome ${ }^{\mathrm{a}}$

\begin{tabular}{|c|c|c|c|c|c|c|c|}
\hline \multirow[b]{2}{*}{ Gene and annotation ${ }^{\mathrm{b}}$} & \multirow[b]{2}{*}{ Size (bp) } & \multicolumn{3}{|c|}{ MiSeq (in vitro) } & \multicolumn{3}{|c|}{ HiSeq (in planta) } \\
\hline & & Reads & $\operatorname{ANC}(\times)$ & $\mathrm{ANC} / r r s$ & Reads & $\mathrm{ANC}(\times)$ & $\mathrm{ANC} / d n a G$ \\
\hline \multicolumn{8}{|l|}{ pXFSL21 } \\
\hline dnaG1, DNA primase & 1,074 & 5,479 & 860 & 0.88 & 5,413 & 579 & 1.00 \\
\hline$y d c E$, programmed cell death toxin & 315 & 661 & 360 & 0.37 & 744 & 252 & 0.44 \\
\hline acr $B$, acriflavine resistance protein & 3,063 & 9,004 & 573 & 0.59 & 6,798 & 290 & 0.50 \\
\hline tet $R$, transcriptional regulator & 618 & 1,581 & 433 & 0.44 & 1,669 & 311 & 0.54 \\
\hline $\operatorname{trbE}$, conjugal transferase $\mathrm{E}$ & 1,812 & 4,892 & 463 & 0.47 & 4,825 & 327 & 0.56 \\
\hline $\operatorname{trbB}$, conjugal transferase B & 882 & 2,327 & 424 & 0.43 & 2,393 & 317 & 0.55 \\
\hline \multicolumn{8}{|l|}{ Chromosome } \\
\hline$r r s, 16 \mathrm{~S}$ ribosomal RNA (rRNA) & 1,545 & 7,943 & 975 & 1.00 & 391,918 & 55,770 & $\mathbf{n} / \mathbf{a}$ \\
\hline $\operatorname{rim} M, 16 \mathrm{~S}$ rRNA processing protein & 513 & 1,501 & 484 & 0.50 & 1,046 & 247 & 0.43 \\
\hline $\operatorname{aroB}, 3$-dehydroquinate synthase & 1,113 & 2,638 & 517 & 0.53 & 2,480 & 296 & 0.51 \\
\hline dnaG1, DNA primase & 1,074 & 5,480 & 860 & 0.88 & 5,420 & 579 & 1.00 \\
\hline$g c v B$, glycine dehydrogenase & 2,946 & 7,810 & 483 & 0.50 & 6,732 & 285 & 0.49 \\
\hline$y f c G$, glutathione $\mathrm{S}$-transferase & 618 & 1,612 & 480 & 0.49 & 1,358 & 265 & 0.46 \\
\hline$L 23 p$, large subunit ribosomal protein & 303 & 743 & 494 & 0.51 & 566 & 209 & 0.36 \\
\hline cysJ, NADPH Sulfite reductase & 1,776 & 4,916 & 499 & 0.51 & 4,190 & 288 & 0.50 \\
\hline Ank1, ankyrin-like protein & 3,288 & 9,200 & 561 & 0.58 & 7,426 & 278 & 0.48 \\
\hline wbiE, glycosyl transferase & 828 & 2,175 & 434 & 0.45 & 1,830 & 265 & 0.46 \\
\hline ppk1, phosphomethyl pyrimidine kinase & 810 & 2,274 & 454 & 0.47 & 2,355 & 324 & 0.56 \\
\hline
\end{tabular}

${ }^{a}$ Reads $=$ mapped reads and $\mathrm{n} / \mathrm{a}=$ not applied because of the extraordinarily high ANC from plant chloroplast genome interference.

b dnaGl and rrs are two-copy genes as used as copy-number references. Data in bold were from two-copy genes. 
procedures such as agarose gel electrophoresis. Copy number could be estimated based on intensity of stained DNA bands (Chen et al. 1992; Projan et al. 1983). However, visualization of low-copynumber plasmids in agarose gels is difficult if the plasmid quantity is not significantly enriched. Adding to the problem in this study is the slow-growth nature of $X$. fastidiosa in vitro. Preparation of large quantities of DNA from slow-growing bacteria is challenging. The Southern blot procedure could increase detection sensitivity
(Chen et al. 1992); however, preknowledge of plasmid sequence or DNA is required, which was not available for the strain Stag's Leap. In this study, we successfully applied NGS technology to detect a single-copy plasmid in strain Stag's Leap. The key to success was the high-throughput capacity of NGS. From a microliter level of DNA sample, NGS (HiSeq or MiSeq) generated a high volume of short-sequence reads that evenly or almost evenly covered the whole $X$. fastidiosa genome over hundreds of times (Table 2). The

TABLE 5. pXFSL21 copy-number $(\mathrm{CN})$ analysis by quantitative polymerase chain reaction ${ }^{\mathrm{a}}$

\begin{tabular}{|c|c|c|c|c|c|c|c|c|}
\hline \multirow[b]{2}{*}{ ORF } & \multirow[b]{2}{*}{ Gene } & \multirow[b]{2}{*}{ Origin } & \multirow[b]{2}{*}{ Primer set ${ }^{\mathrm{b}}$} & \multirow[b]{2}{*}{ Amp (bp) } & \multicolumn{2}{|c|}{ In vitro } & \multicolumn{2}{|c|}{ In planta } \\
\hline & & & & & $\mathrm{Ct}$ value & $\mathrm{CN}$ & $C$ t value & $\mathrm{CN}$ \\
\hline 13 & $a c r B$ & Plasmid & acrB_F-acrB_R & 195 & $17.05 \pm 0.08$ & 0.84 & $29.95 \pm 0.07$ & 1.16 \\
\hline \multirow[t]{2}{*}{15} & tetR & Plasmid & tetR_F-tetR_R & 190 & $15.43 \pm 0.08$ & 1.16 & $26.22 \pm 0.06$ & 1.13 \\
\hline & $G A P D H$ & Chromosome & GAPDH_F-GAPDH_R & 191 & $15.55 \pm 0.07$ & 1.0 & $26.61 \pm 0.03$ & 1.0 \\
\hline
\end{tabular}

a $\mathrm{ORF}=$ open reading frame, $\mathrm{Amp}=$ amplicon size, and $\mathrm{Ct}=$ cycle threshold. $\mathrm{CN}$ was calculated based on Pfaffl (2001).

b Primer efficiencies for $t e t R, a c r B$, and $G A P D H$ were 97,83 , and $99 \%$, respectively.

TABLE 6. Homologs of $y d c D-y d c E$ of pXFSL21 in Xylella fastidiosa and representative bacteria in GenBank database (version 222) ${ }^{\mathrm{a}}$

\begin{tabular}{|c|c|c|c|c|c|c|c|}
\hline & \multirow[b]{2}{*}{ Description $^{\mathrm{b}}$} & \multicolumn{2}{|c|}{$y d c D$} & \multicolumn{2}{|c|}{$y d c E$} & \multirow[b]{2}{*}{ Accession } & \multirow[b]{2}{*}{ Group } \\
\hline & & Query $(\%)$ & Seq $(\%)$ & Query $(\%)$ & Seq $(\%)$ & & \\
\hline \multicolumn{8}{|c|}{$\mathrm{nr} / \mathrm{nt}$ Database } \\
\hline 3 & X. fastidiosa $\mathrm{Fb} 7$ & 48 & 76 & 99 & 70 & СР010051.1 & 2 \\
\hline 4 & X. fastidiosa FB7 plasmid unnamed & 48 & 76 & 99 & 70 & CP014330.1 & 2 \\
\hline 5 & X. fastidiosa J1a12 plasmid pXF51-J1 & 48 & 76 & 99 & 70 & CP009825.1 & 2 \\
\hline 8 & X. fastidiosa Pr8x plasmid pXF39 & 48 & 75 & 99 & 71 & CP009827.1 & 2 \\
\hline \multirow[t]{4}{*}{9} & X. fastidiosa $\mathrm{M} 12$ & 48 & 75 & 100 & 73 & СР000941.1 & 2 \\
\hline & Pseudomonas syringae pv. cerasicola CFBP6109 plasmid PP1 & 100 & 70 & $\mathrm{n} / \mathrm{a}$ & $\mathrm{n} / \mathrm{a}$ & NZ_LT963392.1 & \\
\hline & Xanthomonas citri subsp. citri 03-1638-1-1 plasmid pP2 & $\mathrm{n} / \mathrm{a}$ & $\mathrm{n} / \mathrm{a}$ & 99 & 77 & СР023287.1 & \\
\hline & X. citri subsp. malvacearum MS14003 plasmid unnamed1 & $\mathrm{n} / \mathrm{a}$ & $\mathrm{n} / \mathrm{a}$ & 99 & 77 & СР023160.1 & \\
\hline \multicolumn{8}{|c|}{$\begin{array}{l}\text { Whole-genome } \\
\text { shotgun database }\end{array}$} \\
\hline 4 & X. fastidiosa CVC0256 plasmid pXF-BHR.CVC0256 & 48 & 76 & 99 & 70 & LRVF01000125.1 & 2 \\
\hline 5 & X. fastidiosa CVC0251 plasmid pXF-BHR.CVC0251 & 48 & 76 & 99 & 70 & LRVE01000127.1 & 2 \\
\hline 6 & X. fastidiosa subsp. pauca 11399 plasmid pXF51 & 48 & 76 & 99 & 70 & JNBT01000036.1 & 2 \\
\hline 7 & X. fastidiosa strain BB01 BBA & 48 & 75 & 100 & 74 & MPAZ01000005.1 & 2 \\
\hline 8 & X. fastidiosa subsp. multiplex CFBP8417 & 48 & 75 & 100 & 73 & LUYB01000013.1 & 2 \\
\hline 9 & X. fastidiosa subsp. multiplex CFBP8418 & 48 & 75 & 100 & 73 & LUYA01000012.1 & 2 \\
\hline 10 & X. fastidiosa COF0324 plasmid pXF-BHR-COF0324 & 48 & 75 & 99 & 71 & LRVG01000140.1 & 2 \\
\hline 11 & X. fastidiosa CFBP8073 & 48 & 75 & 100 & 73 & LKES01000047.1 & 2 \\
\hline 12 & X. fastidiosa $\mathrm{CO} 33$ & 48 & 75 & 100 & 73 & LJZW01000035.1 & 2 \\
\hline 13 & $X$. fastidiosa sycamore Sy-VA & 48 & 75 & 100 & 73 & JMHP01000002.1 & 2 \\
\hline 14 & $X$. fastidiosa $6 \mathrm{c}$ plasmid pXF6c & 48 & 75 & 99 & 71 & AXBS02000019.1 & 2 \\
\hline 15 & X. fastidiosa subsp. multiplex Griffin-1 & 48 & 75 & 100 & 73 & AVGA01000012.1 & 2 \\
\hline 16 & X. fastidiosa subsp. multiplex ATCC 35871 & 48 & 75 & 100 & 73 & AUAJ01000014.1 & 2 \\
\hline 17 & X. fastidiosa Dixon ctg82 & 48 & 75 & 100 & 73 & AAAL02000009.1 & 2 \\
\hline
\end{tabular}

a Query = query coverage, Seq = sequence identity, and n/a = not applied.

b Plasmid records are highlighted in bold.

TABLE 7. Homologs of higA-higB of pXFSL21 in Xylella fastidiosa and representative bacteria in GenBank database (version 222)

\begin{tabular}{|c|c|c|c|c|c|c|}
\hline \multirow[b]{2}{*}{ ORF } & \multirow[b]{2}{*}{ Description } & \multicolumn{2}{|c|}{ higA } & \multicolumn{2}{|c|}{$\operatorname{hig} B$} & \multirow[b]{2}{*}{ Accession number } \\
\hline & & Query (\%) & Seq $(\%)$ & Query (\%) & Seq $(\%)$ & \\
\hline \multirow{3}{*}{1} & $\mathrm{nr} / \mathrm{nt}$ Database & & & & & \\
\hline & Whole-genome shotgun database & & & & & \\
\hline & $X$. fastidiosa strain Stag’s Leap & 100 & 100 & 100 & 100 & LSMJ01000015.1 \\
\hline 1 & X. fastidiosa strain Ann-1 & 100 & 99 & 100 & 99 & AAAM04000239.1 \\
\hline
\end{tabular}

a $\mathrm{ORF}=$ open reading frame, Query = query coverage, and Seq = sequence identity. 
short sequence reads were assembled to form long sequence contigs. Candidate plasmid contigs were predicted based on bioinformatics information such as genes involving RDM and CAP. Plasmid circularity was evaluated through read mapping, and confirmed by PCR-Sanger sequencing. Plasmid copy number was readily estimated through ANC analyses and supported by qPCR experiments.

Another significant advantage of the NGS approach is that pXFSL21 was detected and characterized not only from pure in vitro $X$. fastidiosa cultures but also from infected in planta grapevine tissue. This approach is particularly useful for fastidious prokaryote research where pure culture is difficult, or even not possible, to obtain. Indeed, the NGS approach is playing a major role in detection and characterization of circular plasmids or prophages in a nonculturable bacterium, 'Candidatus Liberibacter asiaticus', associated with citrus huanglongbing (Zheng et al. 2018). Interestingly, the culturable property of the $X$. fastidiosa allowed us to validate both in vitro and in planta methods simultaneously (Tables 2 and 4).

Growth of $X$. fastidiosa in grapevine is a natural system in which to study pathogen-host interactions of PD. NGS technology provided an opportunity to study the behavior of the $X$. fastidiosa genome directly in a plant host. pXFSL21 (contig 15) was clearly single copy under both in vitro and in planta conditions (Tables 2 and 4). However, this was not the case for contig 6 (Table 2). The 19,107-bp contig 6 doubled its copy number under in planta condition $(\mathrm{ANC}=940)$ compared with that under in vitro condition $(\mathrm{ANC}=490)$. Annotation showed that contig 6 contained 24 ORFs that encoded exclusively phage or hypothetical proteins, including a phage lysozyme. Detailed analyses on contig 6 are outside the scope of this study and deserve future attention. Yet analyses of pXFSL2 1 and contig 6 have demonstrated the potential research power of an NGS approach.

T-A systems are mechanisms well known for their role in maintaining low-copy-number plasmids in a bacterial population (Dmowski and Jagura-Burdzy 2013; Unterholzner et al. 2013; Yang and Walsh 2017). A single T-A system in a $X$. fastidiosa DNA was described previously (Lee et al. 2014; Stenger et al. 2010). This study detected two T-A system in pXFSL21. The Stag's Leap culture hosting pXFSL21 in this study has been subcultured in PW medium numerous times since 2010. It is apparent that pXFSL21 was consistently maintained or survived through all the subculturing as well as in planta manipulations. For this reason, we assumed that the double T-A systems could have provided a double dosage effect that strengthened the survivability of pXFSL21. However, further experimental validations are needed to prove this theory.

The T-A systems of $y c d D-y c d E$ and higB-higA have been described in multiple bacterial systems (Budde et al. 2006; Pellegrini et al. 2005; Schureck et al. 2014). Both $y d c D-y d c E$ and higB-higA are type II T-A systems (i.e., the toxin is neutralized by binding of the partner antitoxin protein). The proteinaceous nature of the type II system makes it a feasible target for artificial activation of the toxin for pathogen control. Identification of compounds that disrupt T-A complexes would directly activate the toxin, leading to bacterial cell killing (Unterholzner et al. 2013). The two toxin genes are relatively small: $y d c E$ is 315 bp coding for a 104-amino-acid (aa) protein (Fig. 2B) and higB is 279 bp coding for a 92-aa protein (Fig. 2C). The identification of these T-A system genes on a unique plasmid creates the opportunity to clone and express these toxin genes in planta to potentially control PD. The knowledge obtained through NGS along with bioinformatics analyses provides the necessary sequence and genomic structural information to generate targeted experiments on the biology and gene function of an organism.

Due to application of NGS, the GenBank database has accumulated $>40 X$. fastidiosa plasmid sequences and $>40$ of the bacterial whole-genome sequences. The large sequence collections provided a convenient and efficient means for $X$. fastidiosa characterization population wide. For example, the $y d c D-y d c E$ system was found in $X$. fastidiosa strains from different geographical origins and formed two groups: one with $y d c D$ almost identical (100\% length coverage, 98 to $100 \%$ identity) to that in pXFSL21, and the other much different $y d c D$ (48\% length coverage, 70 to $76 \%$ identity) (Table 6). In contrast, higB-higA was limited only to strain Ann-1 and CO33. The two T-A systems could be either plasmid- or chromosome-borne, as in other bacteria (Pandey and Gerdes 2005). Many non-Xylella sequences similar to the four T-A system genes were found. Phylogenetic trees constructed from these sequences were not informative. Instead, the most similar bacteria were listed for phylogenetic reference. Along the line of plasmid characterization, we were not able to identify ori of pXFSL21 with high confidence.

Furthermore, among the five GenBank documented PD strains (i.e., Temecula1, M23, GB514, ATCC 35879, and Stag's Leap), pXFSL21 was only found in the Stag's Leap strain. Given the genetic content of this plasmid, particularly the CAP genes acrA and $\operatorname{acr} B$, predicted to be involved in resistance to toxic compounds, pXFSL21 may be a promising lead for targeted experiments into the function of plasmid located genes and their effect on the biology of $X$. fastidiosa. This plasmid may play a role in the prevalence or virulence specific to the Stag's Leap strain. However, direct experimental evidence is currently lacking. Nevertheless, pXFSL21 could serve as a molecular marker, or an initial point, to study the uniqueness or its role in virulence of the Stag's Leap strain.

\section{ACKNOWLEDGMENTS}

We thank G. Phillips, R. Huerta, and S. Vargas for technical assistance. The mention of trade names or commercial products in this publication is solely for the purpose of providing specific information and does not imply recommendation or endorsement by the U.S. Department of Agriculture. The USDA is an equal opportunity provider and employer.

\section{LITERATURE CITED}

Aziz, R. K., Bartels, D., Best, A. A., DeJongh, M., Disz, T., Edwards, R. A., Formsma, K., Gerdes, S., Glass, E. M., and Kubal, M. 2008. The RAST Server: Rapid annotations using subsystems technology. BMC Genomics 9:75.

Budde, P. P., Davis, B. M., Yuan, J., and Waldor, M. K. 2006. Characterization of a higBA toxin-antitoxin locus in Vibrio cholerae. J. Bacteriol. 189: 491-500.

Burbank, L. P., and Stenger, D. C. 2016. Plasmid vectors for Xylella fastidiosa utilizing a toxin-antitoxin system for stability in the absence of antibiotic selection. Phytopathology 106:928-936.

Buzkan, N., Kocsis, L., and Walker, M. A. 2005. Detection of Xylella fastidiosa from resistant and susceptible grapevine by tissue sectioning and membrane entrapment immunofluorescence. Microbiol. Res. 160:225-231.

Chang, C. J., Garnier, M., Zreik, L., Rossetti, V., and Bové, J. M. 1993. Culture and serological detection of the xylem-limited bacterium causing citrus variegated chlorosis and its identification as a strain of Xylella fastidiosa. Curr. Microbiol. 27:137-142.

Chen, J., Chang, C., and Jarret, R. 1992. Plasmids from Xylella fastidiosa strains. Can. J. Microbiol. 38:993-995.

Chen, J., Groves, R., Civerolo, E., Viveros, M., Freeman, M., and Zheng, Y. 2005. Two Xylella fastidiosa genotypes associated with almond leaf scorch disease on the same location in California. Phytopathology 95:708-714.

Chen, J., Wu, F., Zheng, Z., Deng, X., Burbank, L., and Stenger, D. 2016. Draft genome sequence of Xylella fastidiosa subsp. fastidiosa strain Stag's Leap. Genome Announc. 4:e00240-16.

Coplin, D. L. 1989. Plasmids and their role in the evolution of plant pathogenic bacteria. Annu. Rev. Phytopathol. 27:187-212.

Davis, M. J., French, W. J., and Schaad, N. W. 1981. Axenic culture of the bacteria associated with phony disease of peach and plum leaf scald. Curr. Microbiol. 6:309-314.

Dmowski, M., and Jagura-Burdzy, G. 2013. Active stable maintenance functions in low copy-number plasmids of Gram-positive bacteria II. Postsegregational killing systems. Pol. J. Microbiol. 62:17-22.

Gerdes, K., Rasmussen, P. B., and Molin, S. 1986. Unique type of plasmid maintenance function: Postsegregational killing of plasmid-free cells. Proc. Natl. Acad. Sci. USA 83:3116-3120.

Giampetruzzi, A., Chiumenti, M., Saponari, M., Donvito, G., Italiano, A., Loconsole, G., Boscia, D., Cariddi, C., Martelli, G. P., and Saldarelli, P. 
2015. Draft genome sequence of the Xylella fastidiosa CoDiRO strain. Genome Announc. 3:e01538-14.

Hayes, F. 2003. Toxins-antitoxins: Plasmid maintenance, programmed cell death, and cell cycle arrest. Science 301:1496-1499.

Hopkins, D. 1989. Xylella fastidiosa: Xylem-limited bacterial pathogen of plants. Annu. Rev. Phytopathol. 27:271-290.

Hopkins, D. L. 2001. Xylella fastidiosa. Pages 201-213 in: Laboratory Guide for Identification of Plant Pathogenic Bacteria. N. W. Schaad, J. B. Jones, and W. Chun, eds. American Phytopathological Society, St. Paul, MN.

Kelley, L. A., Mezulis, S., Yates, C. M., Wass, M. N., and Sternberg, M. J. 2015. The Phyre 2 web portal for protein modeling, prediction and analysis. Nat. Protoc. 10:845-858.

Krivanek, A., and Walker, M. 2005. Vitis resistance to Pierce's disease is characterized by differential Xylella fastidiosa populations in stems and leaves. Phytopathology 95:44-52.

Krugner, R., Sisterson, M. S., Chen, J., Stenger, D. C., and Johnson, M. W. 2014. Evaluation of olive as a host of Xylella fastidiosa and associated sharpshooter vectors. Plant Dis. 98:1186-1193.

Lee, M. W., Tan, C. C., Rogers, E. E., and Stenger, D. C. 2014. Toxin-antitoxin systems mqsR/ygi $\mathrm{T}$ and dinJ/relE of Xylella fastidiosa. Physiol. Mol. Plant Pathol. 87:59-68.

Maniatis, T., Fritsch, E., and Sambrook, J. 1982. Molecular Cloning: A Laboratory Manual. Cold Spring Harbor Laboratory Press, Cold Spring Harbor, NY.

Pandey, D. P., and Gerdes, K. 2005. Toxin-antitoxin loci are highly abundant in freeliving but lost from host-associated prokaryotes. Nucleic Acids Res. 33:966-976.

Pellegrini, O., Mathy, N., Gogos, A., Shapiro, L., and Condon, C. 2005. The Bacillus subtilis ydcDE operon encodes an endoribonuclease of the $\mathrm{MazF} /$ PemK family and its inhibitor. Mol. Microbiol. 56:1139-1148.

Pfaffl, M. W. 2001. A new mathematical model for relative quantification in real-time RT-PCR. Nucleic Acids Res. 29:e45.

Pooler, M. R., Hartung, J. S., and Fenton, R. G. 1997. Sequence analysis of a 1296-nucleotide plasmid from Xylella fastidiosa. FEMS Microbiol. Lett. $155: 217-222$.
Projan, S. J., Carleton, S., and Novick, R. P. 1983. Determination of plasmid copy number by fluorescence densitometry. Plasmid 9:182-190.

Saponari, M., Boscia, D., Nigro, F., and Martelli, G. 2013. Identification of DNA sequences related to Xylella fastidiosa in oleander, almond and olive trees exhibiting leaf scorch symptoms in Apulia (Southern Italy). J. Plant Pathol. 95:668.

Schureck, M. A., Maehigashi, T., Miles, S. J., Marquez, J., Cho, S. E., Erdman, R., and Dunham, C. M. 2014. Structure of the Proteus vulgaris HigB(HigA) 2-HigB toxin-antitoxin complex. J. Biol. Chem. 289:1060-1070.

Sengupta, M., and Austin, S. 2011. Prevalence and significance of plasmid maintenance functions in the virulence plasmids of pathogenic bacteria. Infect. Immun. 79:2502-2509.

Stenger, D. C., Lee, M. W., Rogers, E. E., and Chen, J. 2010. Plasmids of Xylella fastidiosa mulberry-infecting strains share extensive sequence identity and gene complement with pVEIS01 from the earthworm symbiont Verminephrobacter eiseniae. Physiol. Mol. Plant Pathol. 74:238-245.

Sternberg, N., and Austin, S. 1981. The maintenance of the P1 plasmid prophage. Plasmid 5:20-31.

Untergasser, A., Nijveen, H., Rao, X., Bisseling, T., Geurts, R., and Leunissen, J. A. 2007. Primer3Plus, an enhanced web interface to Primer3. Nucleic Acids Res. 35:W71-W74.

Unterholzner, S. J., Poppenberger, B., and Rozhon, W. 2013. Toxin-antitoxin systems: Biology, identification, and application. Mob. Genet. Elements 3: Article e26219.

Wallis, C. M., Wallingford, A. K., and Chen, J. 2013. Grapevine rootstock effects on scion sap phenolic levels, resistance to Xylella fastidiosa infection, and progression of Pierce's disease. Front. Plant Sci. 4:502.

Yang, Q. E., and Walsh, T. R. 2017. Toxin-antitoxin systems and their role in disseminating and maintaining antimicrobial resistance. FEMS Microbiol. Rev. 41:343-353.

Zheng, Z., Bao, M., Wu, F., Van Horn, C., Chen, J., and Deng, X. 2018. A type 3 prophage of 'Candidatus Liberibacter asiaticus' carrying a restrictionmodification system. Phytopathology 108:454-461. 